\title{
Предварительные уроки пандемии COVID-19 для системы социального питания
}

\author{
Эдвардс Ростислав Анатольевич \\ Ассоциации предприятий и предпринимателей, работающих в \\ сфере социального питания Ульяновской области \\ Адрес: 432072, город Ульяновск, проспект Академика Филатова, дом 11 \\ E-mail: rostislave@mail.ru
}

\begin{abstract}
В данной статье рассматривается проблема готовности инфраструктуры отрасли социального питания, прежде всего, в сферах образования и здравоохранения, и ее возможность обеспечивать питанием различные категории потребителей в условиях чрезвычайных ситуаций на примере ограничительных мер, введенных в Российской Федерации в 2020 году из-за пандемии коронавируса COVID-19. Анализируется опыт построения индустриальной системы социального питания в СССР, на основании которого делается вывод о том, что в советское время система социального питания проектировалась в качестве дополнительного контура безопасного питания. Автором предлагается подход по модернизации соответствующей инфраструктуры за счет развития полноценных комбинатов питания, распределительных центров с собственной системой логистики и связями с региональными сельхозпроизводителями. Для создания такой системы обосновывается необходимость изменения культуры применения российского законодательства о контрактной системе с целью повышения приоритета качественных критериев над стоимостными, увеличения сроков заключаемых контрактов для привлечения в отрасль частных инвестиций бизнеса.
\end{abstract}

Ключевые слова: социальное питание, инфраструктура, модернизация, развитие, пищеблок, доготовочная, комбинат социального питания, распределительный центр, законодательство о контрактной системе, инвестиции, безопасность, сырье, полуфабрикат, индустриальное питание

Развитие пандемии коронавируса COVID-19 и параллельно разворачивающийся мировой экономический кризис стали своеобразным краш-тестом для многих систем. Правительственные структуры всех стран мира предпринимают целенаправленные меры по стабилизации ситуации. Действия каждой страны имеют принципиальное значения для всего мира: глобализация диктует собственные требования к купированию любых глобально значимых угроз.

Президент Российской Федерации В.В. Путин, в указанных условиях, наделяет дополнительными полномочиями Правительство, которое ужесточает ответственность за нарушение в области ограничительных мер, вводит правила поведения граждан в режиме чрезвычайной ситуации (далее - ЧС). Концепция «Если завтра война?» стала превалировать во многих вопросах над псевдолиберальными ценностями. Обществу и государству пришлось задуматься, а возможно ли в сложившейся правовой системе с учетом механизма взаимодействия государства и бизнеса сформировать отрасли, экономически готовые к серьёзным испытаниям?
К сожалению, зачастую ответ на этот вопрос отрицательный. Не является исключением и отрасль социального питания. Здесь следует сразу оговориться, что как таковой отрасли социального питания в России не существует: в российском экспертном сообществе и бизнес-кругах, занимающихся данным сегментом общественного питания, сложилось лишь устойчивая дефиниция социального питания, не трансформировавшаяся пока в феномен. Впервые автор данной статьи предложил его формализованную интерпретацию его в рамках Первой Всероссийской конференции, посвящённой вопросам школьного питания в ноябре 2019 года: «питание, в организованных коллективах, за которое велика ответственность государства» (Совершенствование системы питания в образовательных организациях: практики, модели, технологии, концепция, 2019).

Если исходить из данного определения, то становится понятно, почему такое питание не может быть только частью или сегментом общественного питания. Обеспечение безопасным здоровым питанием целые группы населения мыслится более важным, нежели ресторанный бизнес, питание в сети кафе и пр. Например, детское питание - от молочной кухни, детских садов, школ 
до загородных лагерей, или лечебное, охватывающее все типы и виды медицинских учреждений и социальных служб. Именно такое социальное питание, сформированное в отдельную отрасль, вертикально-интегрированное, опирающееся на индустриальный подход и самые современные технологии, должно иметь возможность оперативно разворачиваться в полноценную систему в режиме ЧС.

Истоки концепции социального питания в России легко отследить в советских учебниках по товароведению. Так, например, школьное питание стало предметом первого декрета СНК «О бесплатном питании детей» 1919 года, получив свое эволюционировавшее воплощение в ведомственном приказе Министерства торговли СССР 1985 года «О методических указаниях по организации рационального питания учащихся в общеобразовательных школах». Отсюда можно сделать вывод, что подобная система уже проектировалась и создавалась. Отчасти работу такой системы можно в условиях пандемии коронавируса отследить в Ульяновской области, где еще в 2014 году были приняты специальный закон и подзаконные акты, регулирующие отношения в сфере социального питания (О правовом регулировании отдельных вопросов организации социального питания в Ульяновской области, 2014; О некоторых мерах по реализации Закона Ульяновской области «О правовом регулировании отдельных вопросов организации социального питания в Ульяновской области, 2014).

Со специалистами созданной Правительством Ульяновской области автономной некоммерческой организации «Агентство здорового и социального питания» нами был выполнен приблизительный подсчёт продовольствия, необходимого для обеспечения питанием лечебных учреждений региона, в случае их одномоментной максимальной загруженности в соответствии с Приказом Министерства здравоохранения РФ №395н от 21.06.2013 г. (Об утверждении норм лечебного питания, 2013). Пандемия наглядно демонстрирует, что такие пики возможны, особенно в условиях самоизоляции регионов друг от друга. В Таблице 1 приведены данные, пользуясь которыми любой руководитель системы здравоохранения, а также Министерства сельского хозяйства области может ответить на вопрос: «Есть ли в наличии запас данных продуктов, распределительные центры, транспортные возможности, в конце концов нормальные пищеблоки для обеспечения питанием?».
При этом, мощность торговых сетей и специализированных военных запасов учитывать не стоит: у последних другие цели, а торговые сети в условиях кризиса с трудом справляются с решением собственных задач по обеспечению населения продовольствием.

Региональным Министерствам сельского хозяйства необходимо обеспечить наличие современого пункта забоя крупного рогатого скота (так как именно говядина является основным мясным сырьем для социального питания), способного автономно обеспечить подведомственную территорию. К сожалению, далеко не все регионы следуют этой политике.

Вызывает озабоченность и процедура питания в лечебных учреждениях. Введены в действие рекомендации больницам, в которых планируется размещение инфицированных больных. В указанных рекомендациях регламентировано приобретении одноразовой посуды, однако питание до блока будет по-прежнему доставляться из одной кухни, в посуде, которую тщательно подвергнуть термической обработке во многих случаях нет возможности даже на пищеблоке. Высока вероятность, что общий пищеблок будет продолжать работать на сырье и продуктах, которые будут доставляться к нему из различных точек, различными предпринимателями, транспортом, установить за которыми тотальный контроль просто невозможно. При этом специально для таких случаев в мире давно разработана система питания, так называемая модель Cook\&Freeze, применять которую в лечебном питании, на наш взгляд, следует повсеместно, а в подобных случаях - просто необходимо. Однако, так как готовить подобные производственные мощности необходимо заблаговременно, быстро подобное производство не развернуть (Нормативы системы питания Cook\&Chill и Cook\&Freeze, 2020).

Аналогичная ситуация сложилась в системе школьного питания. Ни пандемия, ни рецессия в экономике не только не отменяют подписанный Президентом 1 марта 2020 года Федеральный закон № 47-Ф3 «О внесении изменений в Федеральный закон «О качестве и безопасности пищевых продуктов» и статью 37 Федерального закона «Об образовании в Российской Федерации», который обязывает обеспечить бесплатным питанием всех школьников с 1 по 4 класс, а наоборот, поддерживают его своевременность и актуальность (О внесении изменений в Федеральный закон «О качестве и безопасности пищевых 
Таблица 1

Необходимый запас продуктов питания для учреждений здравоохранения Ульяновской области в случае их одномоментной, максимальной загруженности (нормы указаны для основного варианта диеты, 7000 коек)

\begin{tabular}{|c|c|c|c|}
\hline Наименование продуктов & $\begin{array}{c}\text { По норме за } 1 \\
\text { койко-день, кг }\end{array}$ & $\begin{array}{c}\text { Объем продуктов в } \\
\text { сутки, кг }\end{array}$ & $\begin{array}{c}\text { Объем продуктов } \\
\text { в месяц, кг }\end{array}$ \\
\hline 1 & 2 & 3 & 4 \\
\hline Хлеб ржаной & 0,15 & 1050 & 31500 \\
\hline Хлеб пшеничный & 0,15 & 1050 & 31500 \\
\hline Мука пшеничная & 0,01 & 70 & 2100 \\
\hline Макаронные изделия & 0,02 & 140 & 4200 \\
\hline Крупа всего & 0,08 & 560 & 16800 \\
\hline Картофель & 0,3 & 2100 & 63000 \\
\hline Овощи свежие всего: & 0,3617 & 2531,9 & 75957 \\
\hline Свекла & 0,065 & 455 & 13650 \\
\hline Капуста & 0,1875 & 1312,5 & 39375 \\
\hline лук репчатый & 0,024 & 168 & 5040 \\
\hline Лук зеленый, петрушка, укроп & 0,02 & 140 & 4200 \\
\hline Морковь & 0,07 & 490 & 14700 \\
\hline Огурцы, помидоры свеж. & 0,0152 & 106,4 & 3192 \\
\hline Овощи солёные (капуста, огурцы) & 0,0188 & 131,6 & 3948 \\
\hline Другие овощи (кабачки, перец и другие) & 0,0625 & 437,5 & 13125 \\
\hline Фрукты свежие & 0,15 & 1050 & 31500 \\
\hline Сухофрукты & 0,0204 & 142,8 & 4284 \\
\hline Овощи консер. (зел. гор., кукуруза) & 0,038 & 266 & 7980 \\
\hline Соки овощные, фруктовые & 0,1 & 700 & 21000 \\
\hline Говядина & 0,1277 & 893,9 & 26817 \\
\hline Птица & 0,025 & 175 & 5250 \\
\hline Колбаса варёная, сосиски & 0,012 & 84 & 2520 \\
\hline Рыба, рыбопродукты & 0,0591 & 413,7 & 12411 \\
\hline Творог & 0,0204 & 142,8 & 4284 \\
\hline Сыр & 0,016 & 112 & 3360 \\
\hline Яйцо & 0,02 & 140 & 4200 \\
\hline Кисломолочные напитки & 0,125 & 875 & 26250 \\
\hline Молоко & 0,21 & 1470 & 44100 \\
\hline Масло растительное & 0,02 & 140 & 4200 \\
\hline Масло сливочное & 0,02 & 140 & 4200 \\
\hline Caxap & 0,03 & 210 & 6300 \\
\hline Печенье & 0,02 & 140 & 4200 \\
\hline Сметана & 0,015 & 105 & 3150 \\
\hline Кофе, какао & 0,0014 & 9,8 & 294 \\
\hline Чай & 0,002 & 14 & 420 \\
\hline Дрожжи прессованные & 0,025 & 175 & 5250 \\
\hline Соль & 0,006 & 42 & 1260 \\
\hline Крахмал картофельный & 0,005 & 35 & 1050 \\
\hline Томат паста, томат-пюре & 0,003 & 21 & 630 \\
\hline Шиповник & 0,015 & 105 & 3150 \\
\hline
\end{tabular}


продуктов» и статью 37 Федерального закона «Об образовании в Российской Федерации, 2020). Согласно отчетам, $68 \%$ регионов заявляли о готовности инфраструктуры школьного питания к выполнению закона уже с 1 сентября 2020 года: остается неясным, в этой связи, почему власти ряда регионов не смогли оперативно обеспечить многодетные и малообеспеченные семьи достойными сухими пайками в режиме. Совершенно не случайно, отсюда, В.В. Путин, оценив ситуацию в школьном питании, в своем Послании Федеральному Собранию 15 января 2020 года постановил необходимость ее оптимизации до 2023 года (Послание Президента РФ Федеральному Собранию, 2020).

Архивные документы свидетельствуют, что в России школьное питание мыслилось еще одним контуром безопасного питания, способным функционировать под управлением Единого центра по строгим правилам. Предложенные для его функционирования технологии были прозрачными и экономически обосноваными: более 80\% школьных пищеблоков в стране были трансформированы в кухни-доготовочные (которые, впрочем, стремятся к превращению в столовые полного цикла (О методических указаниях по организации рационального питания учащихся в общеобразовательных школах, 1985).

Но предложенная концепция не коррелирует с требованиями санитарных норм, планировочных решений, действующих на момент строительства СНиПов и СанПиНов. СанПиН 2.4.5.2409-08 «Санитарно-эпидемиологические требования к организации питания обучающихся в общеобразовательных учреждениях, учреждениях начального и среднего профессионального образования» разделяет организации, организующие питание детей, на следующие типы: базовые организации школьного питания (комбинаты школьного питания, школьно-базовые столовые и тому подобное), которые осуществляют закупки продовольственного сырья, производство кулинарной продукции, снабжение ими столовых общеобразовательных учреждений; доготовочные организации общественного питания, на которых осуществляется приготовление блюд и кулинарных изделий из полуфабрикатов и их реализация; столовые образовательных учреждений, работающие на продовольственном сырье или на полуфабрикатах, которые производят и/или реализуют блюда в соответствии с разнообразным по дням недели меню; буфеты - раздаточные, осуществляющие реализацию готовых блюд, кулинарных, мучных кондитерских и булочных изделий.

Пунктом 2.3 того же документа установлено, что столовых образовательных учреждений, работающих на продовольственном сырье и/ или полуфабрикатах, должны быть предусмотрены объемно-планировочные решения, набор помещений и оборудование, позволяющие осуществлять приготовление безопасной, и сохраняющей пищевую ценность, кулинарной продукции, и ее реализацию. Пунктом 2.5 установлено, что объемно-планировочные и конструктивные решения помещений для организаций общественного питания образовательных учреждений должны соответствовать санитарно-эпидемиологическим требованиям, предъявляемым к организациям общественного питания, исключающие встречные потоки сырья, сырых полуфабрикатов и готовой продукции, использованной и чистой посуды, а также встречного движения посетителей и персонала.

При этом Приложением № 1 к вышеобозначенному СанПиН утвержден рекомендуемый минимальный перечень оборудования производственных помещений столовых образовательных учреждений и базовых предприятий питания. Перечнем установлено, что в столовых образовательных организаций, работающих на сырье, должны быть выделены цеха для обработки продукции, которые исключают встречные потоки сырья, сырых полуфабрикатов и готовой продукции (Об утверждении СанПиН 2.4.5.2409-08 «Санитарно-эпидемиологические требования к организации питания обучающихся в общеобразовательных учреждениях, учреждениях начального и среднего профессионального образования, 2008).

В пункте 8.4 СП 2.3.6.1079-01 «Санитарно-эпидемиологические требования к организациям общественного питания, изготовлению и оборотоспособности в них пищевых продуктов и продовольственного сырья» указано, что обработка сырых и готовых продуктов производится раздельно в специально оборудованных цехах. Из технических паспортов здания большинства образовательных организаций следует, что проектом строительства в большинстве случаев изначально не предусматривалось выделение отдельных производственных цехов, а площадь столовой недостаточна для размещения минимального перечня оборудования и исключения встречных потоков сырья, сырых полуфабрикатов и готовой продукции, использованной и чистой посуды, а также встречного движения посетителей и персо- 
нала (О введении в действие санитарных правил СП 2.3.6.1079-01 «Санитарно-эпидемиологические требования к организациям общественного питания, изготовлению и оборотоспособности в них пищевых продуктов и продовольственного сырья, 2001). Об этом говорят и действовавшие в 1970-1990 гг. строительные нормы и правила, в частности СНиП II-65-73 «Общеобразовательные школы и школы-интернаты» (период действия 1974-1987 гг.). В Приложении 2 указанного СНиПа сказано, что при проектировании зданий общеобразовательных организаций кухня-заготовочная (на сырье) проектировалась при количестве классов в количестве 20 шт., при большем числе классов проектировались кухни-доготовочные (на полуфабрикатах) (Нормы проектирования. Общеобразовательные школы и школы-интернаты, 1973). Аналогичные выводы следуют и из положений ВСН 50-86/Госгражданстрой «Общеобразовательные школы и школы-интернаты. Нормы проектирования» (период действия 19861990 гг.), где в таблице № 13 и примечании к ней указаны площади кухни, а также указание на то, что в школах на 4 и более параллелей площади кухонь рассчитаны на размещение оборудования для приготовления пищи на полуфабрикатах (Общеобразовательные школы и школы-интернаты. Нормы проектирования, 1986).

Поэтому, если поднять паспорт любой школы, то станет очевидным нарушение норм СанПиНа в обычных условиях, не говоря уже о режиме карантина или ЧС.

Ассоциация операторов социального питания акцентирует необходимость надстроить указанную систему полноценными комбинатами питания, принимающими и обрабатывающими сырьё, имеющими собственные распределительные центры, отдельные аккредитованные лаборатории, собственную систему логистики и надёжные связи с региональными сельхозпроизводителями. Подобное деление существовало уже в 1985 году прошлого столетия (О методических указаниях по организации рационального питания учащихся в общеобразовательных школах, 1985). В соответствии с пунктами 6.2-6.3 Приказа Министерства торговли СССР от 26.12.1985 № 315 было признано, что целесообразно создавать по территориально-производственному признаку крупные специализированные объединения (комбинаты, тресты) школьного питания, базовым предприятиям которых должны являться, как правило, предприятия (фабрики) полуфабрикатов и кулинарных изделий, снабжающие продукцией все школьные столовые. Оптимальный размер объединений школьного питания, то есть количество входящих в него школьных столовых, определяемое численностью обслуживаемого контингента учащихся, зависит от многих факторов, главными из которых являются производственные мощности предприятий полуфабрикатов и кулинарных изделий. Выбор его мощности определяется соответствующей расчетной численностью обслуживаемого контингента учащихся, которую следует принимать по приведенной Таблице 2 (О методических указаниях по организации рационального питания учащихся в общеобразовательных школах, 1985).

Создание подобной структуры в качестве функционирующей способно обеспечить возможность системы школьного питания в комплексе со всеми остальными направлениями социального питания оперативно реагировать на решение любых задач обеспечения питания, в том числе, и в режиме самоизоляции регионов страны друг от друга. И то, что школьные пищеблоки являются доготовочными, послужит дополнительным «шлюзом безопасности», в качестве коих они и проекти-

Таблица 2

Мощность заготовочных предприятий в зависимости от численности обслуживаемого контингента учащихся

\begin{tabular}{|c|c|}
\hline Расчетная численность учащихся (тысяч) & Мощность предприятий (тонн в смену) \\
\hline \multicolumn{2}{|c|}{ I. Предприятия полуфабрикатов и кулинарных изделий } \\
\hline 10 & 3 \\
\hline 16,6 & 5 \\
\hline 33,3 & 10 \\
\hline \multicolumn{2}{|c|}{ І. Фабрики полуфабрикатов и кулинарных изделий } \\
\hline 50 & 15 \\
\hline 83,3 & 25 \\
\hline 133,3 & 40 \\
\hline
\end{tabular}


ровались. То, что подобная система еще и более экономически выгодна, очевидно, но является предметом отдельного обсуждения.

Прокомментируем псевдолиберальные ценности, упомянутые в начале статьи. Речь идет о так называемой политике ценовой конкуренции в рамках складывающейся культуры применения Федерального закона «О контрактной системе в сфере закупок товаров, работ, услуг для обеспечения государственных и муниципальных нужд» от 05.04.2013 г. N 44-Ф3 (далее - 44-Ф3). Председатель Правительства РФ М.В. Мишустин уже подчеркивал во время заседания Правительства РФ 20 февраля 2020 года, что, к сожалению, в рамках 44-Ф3 соблюдение процедуры зачастую становится важнее результата (Заседание Правительства РФ, 2020). Предложенная законом процедура настолько неповоротливая, что не позволяет медикам оперативно закупить даже банальные маски и респираторы в режиме карантина. Достаточно проанализировать, какое количество торгов было признано несостоявшимися в период режима повышенной готовности.

Известно достаточно много случаев и в социальном питании, в рамках которых общественные расследования о так называемых сговорах привели к существенному искажению процедуры: заказчики, опасаясь претензий со стороны надзорных органов, перестали выставлять какие-либо требования к качеству оказываемой услуги. Что, естественно, не стимулирует бизнес к развитию собственной инфраструктурной базы, основанной на индустриальном подходе.

Другой очевидный перегиб заключается в том, что в социальном питании, несмотря на разъяснение Федеральной антимонопольной службы (ФАС) о возможности объединять в единый лот одну группу товаров и услуг, заказчики старательно избегают и этого. В результате даже конкурсы с ограниченным участием превращаются практически в ценовые аукционы, тогда как в питании цена не может быть приоритетом над качеством. В результате предприниматель, использующий пищеблок не в соответствии с типом и видом, не имеющий никакой производственной базы, с горизонтом планирования не более одного года, оказывается в выигрыше перед теми, кто пытается выстроить полноценную систему безопасного питания, имеющую резерв прочности, в том числе и для неординарных ситуаций. При этом, если вернуться к анализу кейса с обеспечением сухим пайком, то очевидно, что более или менее крупные операторы, обладающие инфра- структурой, справились с этой проблемой и более оперативно, и более качественно. Операторы питания в Ульяновской области провели закупки продуктов и начали выдачу пайков уже на второй день после принятия такого решения на уровне региона. Стоит отметить, что операторы при закупках продуктов в значительных объемах обеспечивают более низкие цены, а, значит, за одну и ту же сумму способны предоставить сухой паёк большего объема.

Становится понятным, что для кардинального изменения ситуации в кратчайшие сроки необходимо перейти к режиму долгосрочных контрактов в системе социального питания, что создаст условия для инвестирования в данную отрасль. Перестать опасаться укрупнения операторов социального питания и их работы сразу в нескольких сегментах, например, в дошкольном, школьном и лечебном питании. Нужно понимать, что укрупнение операторов позволяет создавать всю необходимую инфраструктуру, о которой говорилось выше. При проведении конкурсных процедур необходимо либо совсем перейти на ценовые переговоры, либо прописать методические рекомендации, согласованные с ФАС России и направленные на формирование комбинатов социального питания, заводов, фабрик и трестов, использующих индустриальный подход в организации питания. И, конечно, разработать алгоритм действий и прописать отдельные инструкции для использования системы питания в различных кризисных ситуациях.

\section{Литература}

I Всероссийская конференция «Совершенствование системы питания в образовательных организациях: практики, модели, технологии, концепция». Ульяновск: УлГПУ им. И.Н. Ульянова. URL: https://hf.kursobr.ru/expertseminar/ (дата доступа: 21.02.2020).

Декрет Совета Народных Комиссаров «О бесплатном детском питании» от 19.05.1919 г. URL: http://istmat.info/node/37921 (дата обращения: 27.01.2020).

Приказ Министерства торговли СССР № 315 от 26.12.1985 г. «О методических указаниях по организации рационального питания учащихся в общеобразовательных школах». URL: http:// www.libussr.ru/doc_ussr/usr_13084.htm (дата обращения: 13.02.2020).

Закон Ульяновской области № $105-30$ от 07.07.2014 г. «О правовом регулировании от- 
дельных вопросов организации социального питания в Ульяновской области». URL: http:// docs.cntd.ru/document/463707165 (дата обращения: 22.02.2020).

Постановление Правительства Ульяновской области № 390-П от 02.09.2014 г. «О некоторых мерах по реализации Закона Ульяновской области «О правовом регулировании отдельных вопросов организации социального питания в Ульяновской области». URL: http:// docs.cntd.ru/document/463707801 (дата обращения: 13.02.2020).

Приказ Министерства здравоохранения РФ № 395н от 21.06.2013 г. «Об утверждении норм лечебного питания». URL: http://docs.cntd. $\mathrm{ru}$ /document/499029879 (дата обращения: 22.02.2020).

Нормативы системы питания Cook\&Chill и Cook\&Freeze. URL: https://www.foodcost.ru/ infoteca/normative/?ELEMENT_ID=10117 (дата обращения: 20.02.2020).

Федеральный закон от 01.03.2020 г. № 47-Ф3 «О внесении изменений в Федеральный закон «О качестве и безопасности пищевых продуктов» и статью 37 Федерального закона «Об образовании в Российской Федерации». URL: http://publication.pravo.gov.ru/Document/ View/0001202003010004 (дата обращения: 13.03.2020).

Послание Президента РФ Федеральному Собранию 15 января 2020 года. URL: http:// kremlin.ru/events/president/news/62582 (дата обращения: 22.02.2020).
Постановление Главного государственного санитарного врача РФ от 23 июля 2008 года N 45 «Об утверждении СанПиН 2.4.5.2409-08«Санитарно-эпидемиологическиетребования $\mathrm{K}$ организации питания обучающихся в общеобразовательных учреждениях, учреждениях начального и среднего профессионального образования». URL: http://docs. cntd.ru/document/902113767 (дата обращения: 15.02.2020).

Постановление Главного государственного санитарного врача РФ от 8 ноября 2001 года N 31 «O введении в действие санитарных правил СП 2.3.6.1079-01 «Санитарно-эпидемиологические требования к организациям общественного питания, изготовлению и оборотоспособности в них пищевых продуктов и продовольственного сырья». URL: http://docs. cntd.ru/document/901802127 (дата обращения: 12.01.2020).

СНиП ІІ-65-73 «Нормы проектирования. Общеобразовательные школы и школы-интернаты». URL: http://docs.cntd.ru/ document/1200034736 (дата обращения: 18.02.2020).

ВСН 50-86/Госгражданстрой «Общеобразовательные школы и школы-интернаты. Нормы проектирования». URL: http://docs.cntd.ru/ document/1200037309 (дата обращения: 17.02.2020).

Заседание Правительства РФ 20 февраля 2020 года. URL: http://government.ru/meetings/39001/ stenograms/ (дата обращения: 22.02.2020). 


\title{
Preliminary Lessons of the COVID-19 Pandemic for the Social Nutrition System
}

\author{
Rostislav A. Edvars \\ Association of enterprises and entrepreneurs working in the field of \\ social nutrition of the Ulyanovsk region \\ 11 Akademika Filatov Avenue, Ulyanovsk, 432072, Russian Federation \\ E-mail: rostislave@mail.ru
}

\begin{abstract}
This article examines the problem of readiness of the infrastructure of the social nutrition industry, primarily in the fields of education and health, and its ability to provide food to various categories of consumers in emergency situations, using the example of restrictive measures introduced in the Russian Federation in 2020 due to the COVID-19 coronavirus pandemic. The article analyzes the experience of building an industrial system of social nutrition in the USSR, on the basis of which it is concluded that in Soviet times the social nutrition system was designed as an additional circuit of safe nutrition. The author suggests an approach to modernize the corresponding infrastructure by developing fullfledged food processing plants, distribution centers with their own logistics system and connections with regional agricultural producers. To create such a system, the author justifies the need to change the culture of applying Russian legislation on the contract system in order to increase the priority of quality criteria over cost criteria, and to increase the terms of contracts to attract private business investment to the industry.
\end{abstract}

Keywords: social nutrition, infrastructure, modernization, development, food supply, pre-procurement, social nutrition plant, distribution center, legislation on the contract system, investment, security, raw materials, semi-finished products, industrial nutrition

\section{References}

I Vserossijskaya konferenciya «Sovershenstvovanie sistemy pitaniya $\mathrm{v}$ obrazovatelnyh organizaciyah: praktiki, modeli, tekhnologii, koncepciya» [I All-Russian conference "Improving the nutrition system in educational organizations: Practices, models, technologies, concept"]. Ulyanovsk: UlSPU. URL: https://hf.kursobr.ru/expert-seminar/ (accessed 21.02.2020).

Dekret Soveta Narodnyh Komissarov «O besplatnom detskom pitanii» ot 19.05.1919 g. [Decree of the Council of People's Commissars "On free baby food” from 19.05.1919]. URL: http://istmat.info/ node/37921 (accessed 27.01.2020).

Prikaz Ministerstva torgovli SSSR № 315 ot 26.12.1985 g. «O metodicheskih ukazaniyah po organizacii racionalnogo pitaniya uchashchihsya v obshcheobrazovatelnyh shkolah» [Order of the Ministry of trade of the USSR No. 315 from 26.12.1985 "On methodological guidelines for the organization of rational nutrition of students in secondary schools"]. URL: http://www.libussr.ru/ doc_ussr/usr_13084.htm (accessed 13.02.2020).

Zakon Ulyanovskoj oblasti № $105-\mathrm{ZO}$ ot 07.07 .2014 g. «O pravovom regulirovanii otdelnyh voprosov organizacii socialnogo pitaniya $\mathrm{v}$ Ulyanovskoj oblasti» [Law of the Ulyanovsk region No. 105-ZO from 07.07.2014 "On the legal regulation of certain issues of social nutrition organization in the Ulyanovsk region"]. URL: http://docs.cntd.ru/document/463707165 (accessed 22.02.2020).

Postanovlenie Pravitelstva Ulyanovskoj oblasti № 390-P ot 02.09.2014 g. «O nekotoryh merah po realizacii Zakona Ulyanovskoj oblasti «O pravovom regulirovanii otdelnyh voprosov organizacii socialnogo pitaniya v Ulyanovskoj oblasti» [Resolution of the Government of the Ulyanovsk region No. 390-P from 02.09.2014 "On some measures to implement the Law of the Ulyanovsk region "On legal regulation of certain issues of social nutrition in the Ulyanovsk region"]. URL: http://docs.cntd.ru/document/463707801 (accessed 13.02.2020).

Prikaz Ministerstva zdravoohraneniya RF № 395n ot 21.06.2013 g. «Ob utverzhdenii norm lechebnogo pitaniya» [Order of the Ministry of health of the Russian Federation No. 395n from 21.06.2013 “On approval of medical nutrition standards"]. URL: http://docs.cntd.ru/document/499029879 (accessed 22.02.2020).

Normativy sistemy pitaniya Cook\&Chill i Cook\&Freeze [Regulations of the nutrition supply system Cook\&Chill and Cook\&Freeze]. 
URL: https://www.foodcost.ru/infoteca/normative/?ELEMENT_ID=10117 (accessed 20.02.2020).

Federalnyj zakon ot 01.03.2020 g. № 47-FZ «O vnesenii izmenenij v Federalnyj zakon «O kachestve i bezopasnosti pishchevyh produktov» i statyu 37 Federalnogo zakona «Ob obrazovanii v Rossijskoj Federacii» [Federal law No. 47-FZ from 01.03.2020 "On amendments to the Federal law "On the quality and safety of food products" and article 37 of the Federal law "On education in the Russian Federation"]. URL: http://publication.pravo.gov.ru/Document/View/0001202003010004 (accessed 13.03.2020).

Poslanie Prezidenta RF Federalnomu Sobraniyu 15 yanvarya 2020 goda [Message of the President of the Russian Federation to the Federal Assembly on January 15, 2020]. URL: http://kremlin.ru/events/ president/news/62582 (accessed 22.02.2020).

Postanovlenie Glavnogo gosudarstvennogo sanitarnogo vracha RF ot 23 iyulya 2008 goda $\mathrm{N} \quad 45 \ll \mathrm{Ob}$ utverzhdenii SanPiN 2.4.5.240908 «Sanitarno-epidemiologicheskie trebovaniya $\mathrm{k}$ organizacii pitaniya obuchayushchihsya v obshcheobrazovatelnyh uchrezhdeniyah, uchrezhdeniyah nachalnogo i srednego professionalnogo obrazovaniya» [Resolution of the Chief state sanitary doctor of the Russian Federation from July 23, $2008 \mathrm{~N} 45$ "About the approval of SanPiN 2.4.5.2409-08 "Sanitary and epidemiological requirements for catering of students in general education institutions, institutions of primary and secondary vocational education"]. URL: http://docs.cntd.ru/document/902113767 (accessed 15.02.2020).
Postanovlenie Glavnogo gosudarstvennogo sanitarnogo vracha RF ot 8 noyabrya 2001 goda $\mathrm{N}$ 31 «O vvedenii v dejstvie sanitarnyh pravil SP 2.3.6.1079-01 «Sanitarno-epidemiologicheskie trebovaniya $\mathrm{k}$ organizaciyam obshchestvennogo pitaniya, izgotovleniyu i oborotosposobnosti $\mathrm{v}$ nih pishchevyh produktov i prodovolstvennogo syrya» [Resolution of the Chief state sanitary doctor of the Russian Federation from November 8, $2001 \mathrm{~N} 31$ "On the introduction of sanitary rules SP 2.3.6.1079-01 "Sanitary and epidemiological requirements for public catering organizations, production and turnover of food products and food raw materials in them"]. URL: http://docs.cntd.ru/ document/901802127 (accessed 12.01.2020).

SNiP II-65-73 «Normy proektirovaniya. Obshcheobrazovatelnye shkoly i shkoly-internaty» [SNiP II-65-73 "Design standards. Secondary schools and boarding schools"]. URL: http:// docs.cntd.ru/document/1200034736 (accessed 18.02.2020).

VSN

50-86/Gosgrazhdanstroj «Obshcheobrazovatelnye shkoly i shkoly-internaty. Normy proektirovaniya» [VSN 50-86/ Gosgrazhdanstroy "Secondary schools and boarding schools. Design standards"]. URL: http:// docs.cntd.ru/document/1200037309 (accessed 17.02.2020).

Zasedanie Pravitelstva RF 20 fevralya 2020 goda [Meeting of the Government of the Russian Federation on February 20, 2020]. URL: http:// government.ru/meetings/39001/stenograms/ (accessed 22.02.2020). 